\title{
Physical modelling of the interaction between powder avalanches and defence structures
}

\author{
F. Naaim-Bouvet ${ }^{1}$, M. Naaim ${ }^{1}$, M. Bacher ${ }^{1,2}$, and L. Heiligenstein ${ }^{1}$ \\ ${ }^{1}$ Cemagref, Torrent and Avalanche Research Unit, 2 rue de la Papeterie, BP 76, F-38402 Saint-Martin-d'Hères, France \\ ${ }^{2}$ WLS-BOKU, Institute of Torrent and Avalanche Control, Universität für Bodenkultur, Peter-Jordanstrasse, A-1190 Vienna, \\ Austria
}

Received: 20 September 2001 - Accepted: 5 February 2002

\begin{abstract}
In order to better understand the interaction between powder snow avalanches and defence structures, we carried out physical experiments on small-scale models. The powder snow avalanche was simulated by a heavy salt solution in a water tank. Quasi two-dimensional and threedimensional experiments were carried out with different catching dam heights. For the reference avalanche, the velocity just behind the nose in the head was greater than the front velocity. For the 2-D configuration, the ratio $U_{\max } / U_{\text {front }}$ was as high as 1.6, but it depends on the height. For the 3-D configuration, this ratio differed slightly and was even greater (up to 1.8). The vertical velocity rose to $106 \%$ of the front velocity for the 3-D simulation and 74\% for the 2-D simulation. The reduction in front velocity due to the presence of dams was an increasing function of the dam height. But this reduction depended on topography: dams were more effective on an open slope avalanche (3-D configuration). The ratio $U_{\max } / U_{\text {front }}$ was an increasing function of the dam's height and reached a value of 1.9. The obstacle led to a reduction in vertical velocity downstream of the vortex zone.
\end{abstract}

\section{Introduction and objectives of the studies}

Depending on their flow behaviour, avalanches can be classified as dense-flow avalanches or powder snow avalanches. In the latter case, avalanches consist of ice particle suspended in air. They occur as a dust cloud at the top of flowing avalanches under certain conditions, i.e. when the snow is cold, dry and of low cohesion. An avalanche is considered a pure powder snow avalanche when there is no dense core on the bottom of the flow (MacClung and Schaerer, 1993). The transition from a dense flow avalanche to a powder snow avalanche is not fully understood. Under certain conditions, this suspension may reach extensions of $1000 \mathrm{~m}$ in length, $500 \mathrm{~m}$ in width and over $100 \mathrm{~m}$ in height, with a density of 2

Correspondence to: F. Naaim-Bouvet

(florence.naaim@cemagref.fr)
$5 \mathrm{~kg} / \mathrm{m}^{3}$ (Nishimura et al., 1995). A powder snow avalanche may reach flow velocities of up to $100 \mathrm{~m} / \mathrm{s}$ and exert pressure loads on obstacles amounting to $10-50 \mathrm{kPa}$ (Nishimura et al., 1995).

In spite of significant efforts, the dynamics of powder snow avalanches is not well known due to the lack of field experiments with valid measurements. Nonetheless, teams in Norway, Japan and Switzerland have made systematic investigations and have succeeded in obtaining sets of valuable data. But these studies did not take the interaction with the defense structures into account. Improving the knowledge of avalanche behaviour near the obstacle would be useful for end-users. For this reason, a part of the European project CADZIE (Catastrophic Avalanches Defence Structures and Zoning in Europe) is dedicated to the study of the interaction between powder avalanches and obstacles.

It is obvious that it is preferable to obtain data from the process itself. But if this is not possible, as seen previously, laboratory experiments remain a good option: there is no limit to the number of experiments that can be conducted and initial and boundary conditions can be systematically varied. There are two advantages to performing laboratory experiments:

- it is possible to extract results from small-scale to fieldscale even if it remains difficult to find an appropriate simulation;

- it is possible to validate numerical simulations with a set of valuable data.

In this paper, we will introduce the experiments and the main results obtained on the interaction of 2-D and 3-D powder avalanches with catching dams simulated in a water tank. The comparison with numerical simulations will be the subject of a further communication. 


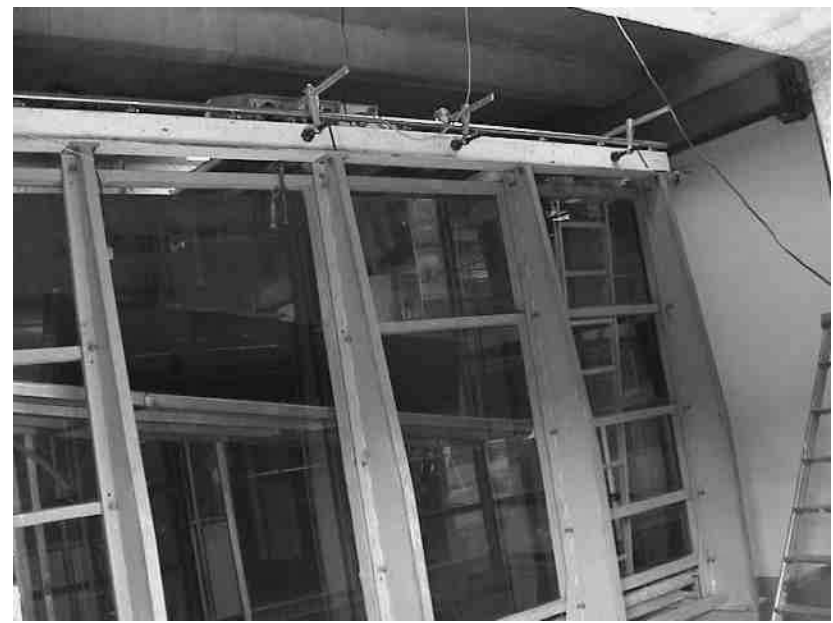

Fig. 1. A general view of the water tank with the submerged channel.

\section{Previous studies}

2.1 Physical modelling: Different approaches and similitude requirements

In the past, several attempts have been made to simulate a powder avalanche. It is possible to distinguish three different approaches: heavy fluid in water, two-phase simulation in water, two-phase simulation in air.

\subsubsection{Heavy fluid in water}

Hopfinger and Tochon-Danguy (1977) and later Beghin (1991) employed a density, gravity or turbidity current concept. The avalanche consists of a heavy fluid that is dispersing in a lighter one. In water-tank experiments, the injection could either be continuous or of short duration, as in our experiments. In the case of a short duration injection, called "inclined thermal" (Hopfinger and Tochon-Danguy, 1977) or "buoyant cloud" (Beghin, 1991), only a head (without a quasi-steady layer) is established, representing a "short" avalanche. In the continuous injection, an inclined gravity current representing a long avalanche is observed, in which the body flow determines the front velocity. When the Reynolds number is sufficiently high, similarity is respected if the densimetric Froude number $\frac{U}{\sqrt{9 H \frac{\Delta \rho}{\rho}}}$ and the density ratio of the current to the ambient fluid $\frac{\Delta \rho}{\rho}$ are respected (where $U$ is the down slope velocity, $H$ is the flow height, and $\frac{\Delta \rho}{\rho}$ is the relative density difference). Fulfilling both numbers in the laboratory means that a very high velocity is necessary, which calls for considerable channel dimensions. As a result, a distortion in the density ratio is taken into account. In the laboratory, salt suspensions or solid particles in water with a density ratio ranging up to 1.2 are used, whereas for powder avalanches, this ratio is on the order of 10 . In the laboratory,

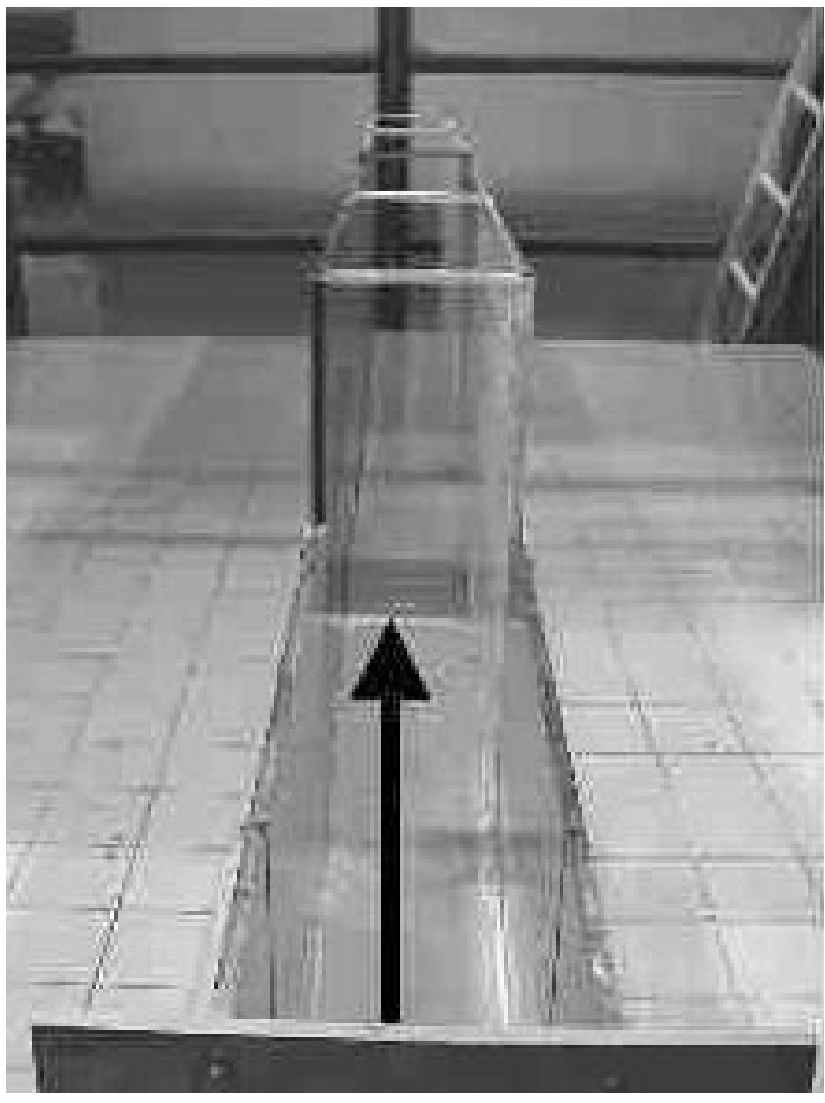

Fig. 2. Two-dimensional channel.

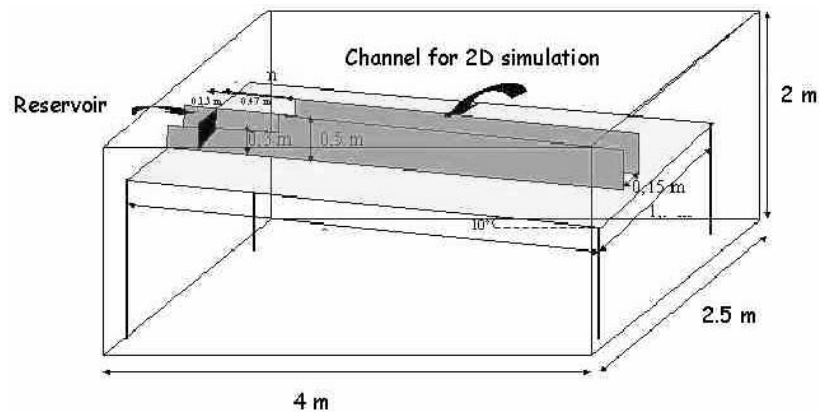

Fig. 3. Schematic drawing of the water tank with the submerged channel.

the flow satisfies the Boussinesq approximation (i.e. density ratio close to 1 ), while this is not the case in real avalanches.

\subsubsection{Two-phase simulation in water}

The previous models, based on a density current, can only be used if particle settling is of marginal importance. In order to investigate the run-out zone of a powder avalanche, where phase separation is of great importance, Hermann and Hutter (1991) developed a two-phase physical model. In this case, powder snow was simulated by a turbulent suspension flow of polystyrene particles in water. The similarity was preserved by the conservation of the densimetric Froude num- 

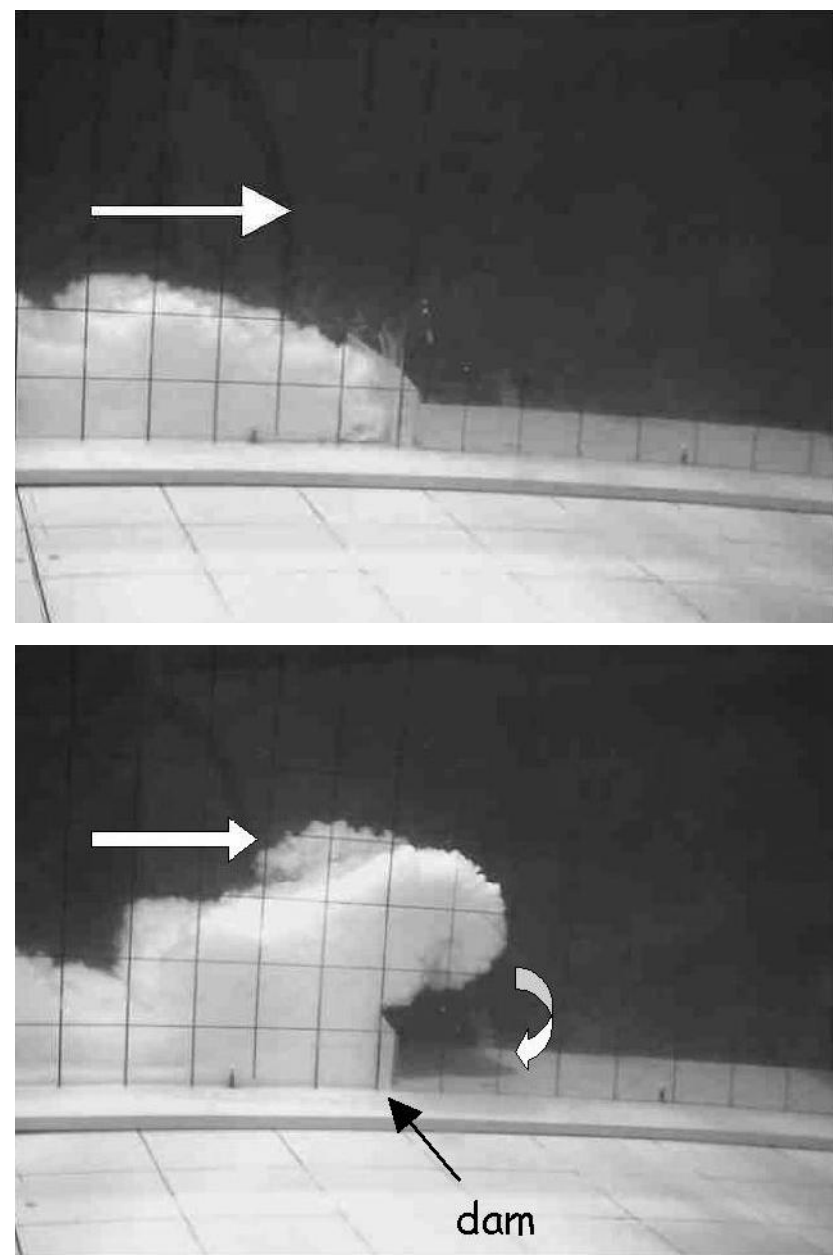

Fig. 4. Two-dimensional avalanche upstream of the obstacles.

ber and the ratio of downstream velocity to free-fall velocity $\frac{U}{U_{\text {fall }}}$ (where $U_{\text {fall }}$ is the free-fall velocity of the particles). A strong distortion of the density ratio was also unavoidable in this type of experiment.

\subsubsection{Two-phase simulation in air}

In the experiments carried out by Bozhinskiy and Sukhanov (1998), the dense avalanche was modelled with dry powder materials. The authors considered the simplest mathematical model of a snow avalanche as a material point and obtained the adimensional parameters from this equation. Thus, they started from dense flow and also observed the formation of the powder cloud. In fact, the determined criteria do not allow the description of the propagation of the aerosol cloud, but the authors considered that they could estimate the effects connected with the genesis of the cloud when an avalanche body enters a deceleration zone using this set of parameters.

\subsection{Interaction between powder avalanches and dams}

Research dealing with the interaction between a gravity current and obstacles is scare. A first attempt was made by
Transducer:

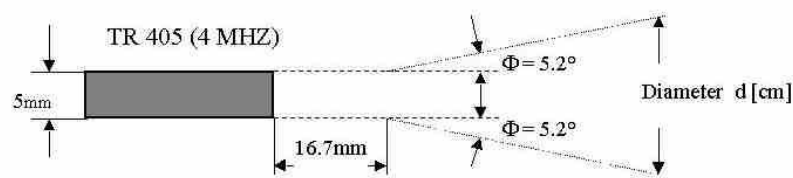

Fig. 5. Transducer with apex angle of the acoustic field.

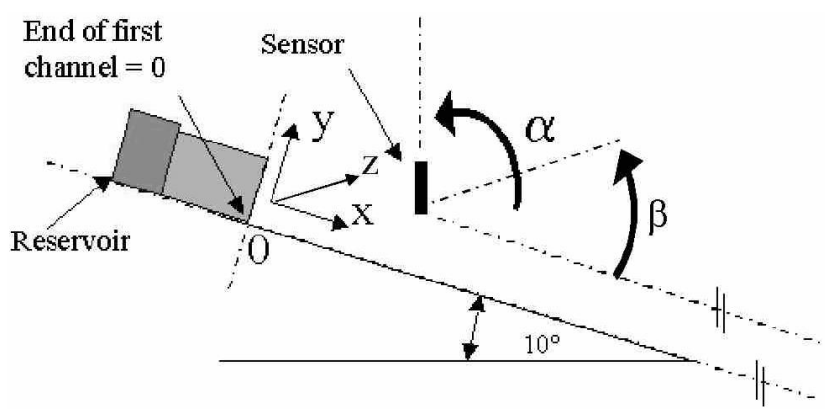

Fig. 6. Notation.

Hopfinger and Tochon-Danguy (1977) in the 1970s. Later, a series of experiments studying unsteady gravity current flow over deflecting and catching dams was conducted at Cemagref by Beghin and Closet (1990) and Augé et al. (1995) for 2-D and 3-D configurations. Similar experiments as those done by Beghin and Closet (1990) were carried out by Keller and Issler (1996) with two-phase flow, using ultrasonic transducers and the Doppler effect for measuring particle velocities and concentrations inside the flow and near the dam. More recently, Lane-Serff et al. (2000) studied the effect of a steady gravity current on an obstacle (a ridge covering the full width of the tank, 2-D configuration). Beghin and Closet (1990) and Lane-Serff et al. (2000) only had access to the front velocity and could not investigate the velocity inside the gravity current.

\section{Experimental set-up and measurement devices}

\subsection{Water tank and operating procedure}

The experimental set-up consisted of a 4- $\mathrm{m} \times 2-\mathrm{m} \times 4.5-\mathrm{m}$ water tank with glass walls (Figs. 1-3). Buoyant clouds flow along an inclined plane from a small immersed tank (length $20 \mathrm{~cm}$, width $15 \mathrm{~cm}$, capacity 41 ) with a release gate. Powder avalanches were simulated by a heavy fluid (salt water plus kaolin) which was dispersing into a lighter one. The density of salt water was 1.185 , but the density of heavy fluid was 1.2. By adding kaolin, the gravity current in the water tank could be made visible. Kaolin was also necessary because ultrasonic methods can only measure the particles within the suspension. In fact, the simulated avalanche was more a puff of non-continuous injected density than a current of heavy fluid: a finite volume of heavy fluid was released instantaneously from the small immersed tank. Contrary to what oc- 


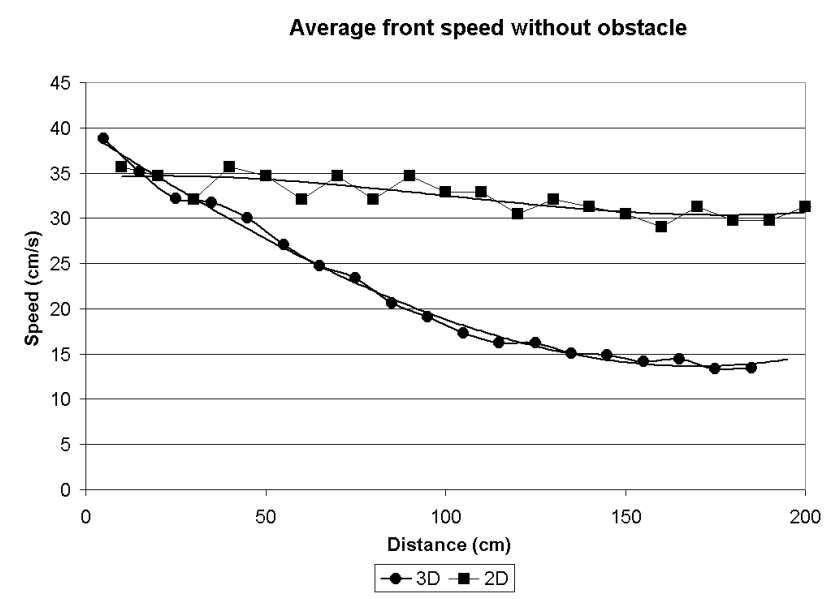

Fig. 7. Reference avalanche front speed for 2-D and 3-D configurations.

curs in nature, the avalanches in laboratory simulation started as powder avalanches. Furthermore, the entrainment of particles was not simulated. 3-D and 2-D simulations were performed. In the 2-D configuration, the avalanche track was confined to a channel (length $285 \mathrm{~cm}$, width $15 \mathrm{~cm}$, height $50 \mathrm{~cm}$ ). In the 3-D configuration, the avalanche track was first confined to a small channel (length $47 \mathrm{~cm}$, width $15 \mathrm{~cm}$, height $30 \mathrm{~cm}$ ) before flowing down the inclined plane (length $300 \mathrm{~cm}$, width $190 \mathrm{~cm}$ ), in order to represent the effect of an avalanche path upstream of the run-out zone. The experiments were carried out with an obstacle representing a model of a defense structure called a dam, which was mounted on the floor and placed perpendicular to the obstacle and to the flow, and set up $97 \mathrm{~cm}$ from the gate perpendicular to the plane and perpendicular to the channel axis, which is the flow. This obstacle, with a height up to $8 \mathrm{~cm}$ was $50 \mathrm{~cm}$ wide in the 3-D configuration. In the 2-D simulation, however, it obstructed the channel. Runs were made along a constant slope of $10^{\circ}$. The initial volume in the release tank was 21 for every trial. We determined experimentally that the highly turbulent nature of the avalanches required the ensemble averaging over five identical experiments (see Fig. 7). We have to mention that our experiments did not contain the so-called saltation layer. Among practitioners and specialists there is considerable uncertainty concerning the effect of a dam on the potentially very destructive saltation layer.

\subsection{Measurement techniques}

Two cameras were used (top and side views) to obtain the height, length, width and the shape of flow, together with the front velocity. The Doppler ultrasonic velocimetry measured the component of the particle velocity vector in the direction of the transducer. The principle of this sensor is based on the change in frequency of an acoustic wave resulting from the movement of particles present in the heavy fluid.

In the zone between the head of the transducer and a distance of $16.7 \mathrm{~mm}$, the acoustic field is basically cylindrical,

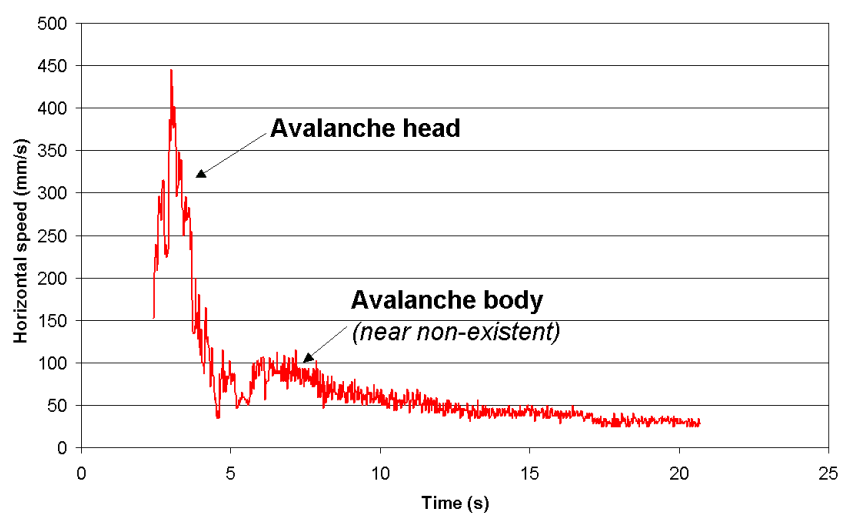

Fig. 8. Average values of horizontal velocity of five single experiments in 2-D configuration.

with a diameter of $5 \mathrm{~mm}$. In the far field zone, the intensity of the acoustic field varies as the inverse of the square of the distance from the transducer and oscillates in the plane perpendicular to the axis of propagation (see Fig. 5). Contrary to transducers used by Hermann and Hutter (1991) and Keller (1995), it was not possible in our case (transducers and expanded ultrasonic unit were manufactured by another company) to determine the particle concentration.

An array of two transducers coupled with the expanded ultrasonic unit was used in the experiments. We plan to buy five other transducers in the future (second phase of the CADZIE project), in order to complete the measurements of speed profiles of the flow. Measurements with only two transducers forced the number of experiments to increase, as it was only possible to record two measurement points simultaneously.

We have to keep in mind that the ultrasonic unit allows to measure the component of the particle velocity vector only in the direction of the transducer. This is why two procedures were followed:

- in the first, profiles are taken along a line perpendicular to the inclined plane $\left(\alpha=0^{\circ}, \beta=0^{\circ}\right)$ at three different positions: $x=46 \mathrm{~cm}, x=96 \mathrm{~cm}$ and $x=146 \mathrm{~cm}$ from point 0 (end of the first channel, see Fig. 6), in order to determine the change in horizontal velocity at different heights in the avalanche. Along the $y$-axis, we established three positions for our measurements according to the lower transducer: $y=0.7 \mathrm{~cm}, y=2.7 \mathrm{~cm}$ and $y=8.7 \mathrm{~cm}$. As two transducers are mounted at the same supporter, measurements are taken simultaneously both for the lower and the upper transducer. Positions for the upper one are given by the fixed distance of $4 \mathrm{~cm}$ between the two transducers $(y=4.7 \mathrm{~cm}, y=6.7 \mathrm{~cm}$ and $y=12.7 \mathrm{~cm}$ );

- in the second, only one transducer was vertically set up $\left(\alpha=90^{\circ}, \beta=0^{\circ}\right)$ to the inclined plane. This allowed one to determine the change in vertical velocity 
Table 1. Dimensionless numbers in nature and in laboratory experiments (Hermann and Hutter, 1991)

\begin{tabular}{lcc}
\hline & Nature & Laboratory \\
\hline Relative density difference $\frac{\Delta \rho}{\rho}$ & 4 & 0.2 \\
Reynolds number Re & $10^{8}$ & $10^{4}$ \\
Densimetric Froude number $\frac{U}{\sqrt{g H \frac{\Delta \rho}{\rho}}}$ & 5 & 5 \\
\hline
\end{tabular}

at three different positions $(x=50 \mathrm{~cm}, x=96 \mathrm{~cm}$ and $x=146 \mathrm{~cm}$ from the origin) at different heights in the avalanche.

A specific distance between the sampling volume and the transducer can be selected; it was chosen as a compromise between a small sampling volume (short distance) and a small influence of the transducer on the measured flow (long distance). We have fixed this distance to $4 \mathrm{~cm}$ in the first procedure. Thus, the sampling volume has the shape of a disk $9 \mathrm{~mm}$ in diameter and $0.75 \mathrm{~mm}$ in height. The temporal resolution was of $21.4 \mathrm{~ms}$.

\subsection{Similitude requirements}

In our experiments, the following dimensionless numbers compared with those from nature were used (see Table 1).

As said previously, the similarity between the real powder snow avalanche and the simulated powder snow avalanche is achieved by the conservation of the densimetric Froude number. The Reynolds number is very high for both processes in nature and in the laboratory. Since the flow is fully turbulent, it does not depend on the Reynolds number. But the relative density difference differs by orders of magnitude in natural and laboratory avalanches. In fact, mercury is sufficiently dense with respect to the density ratio of powder snow avalanche (even at small scale, it would run pretty fast in water, but was not suitable for the users).

Nevertheless, according to Hopfinger and Tochon-Danguy (1977), the air entrainment rate depends primarily on the internal Froude Number and the large density variation in an avalanche only reduces the drag resulting from the air entrainment. In order for this drag to dominate over the wall shear stress, the slope angle must be greater than a certain minimum value, which is approximately $5^{\circ}$ for a low density flow.

\section{Main results}

Before dealing with the effect of dams, it is first of all necessary to treat the avalanche without a dam. This kind of avalanche will be called the reference avalanche.

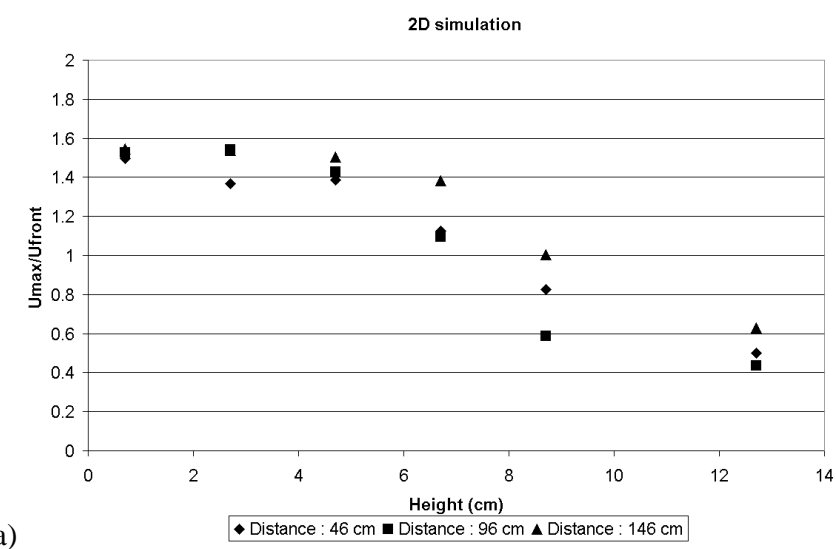

(a)

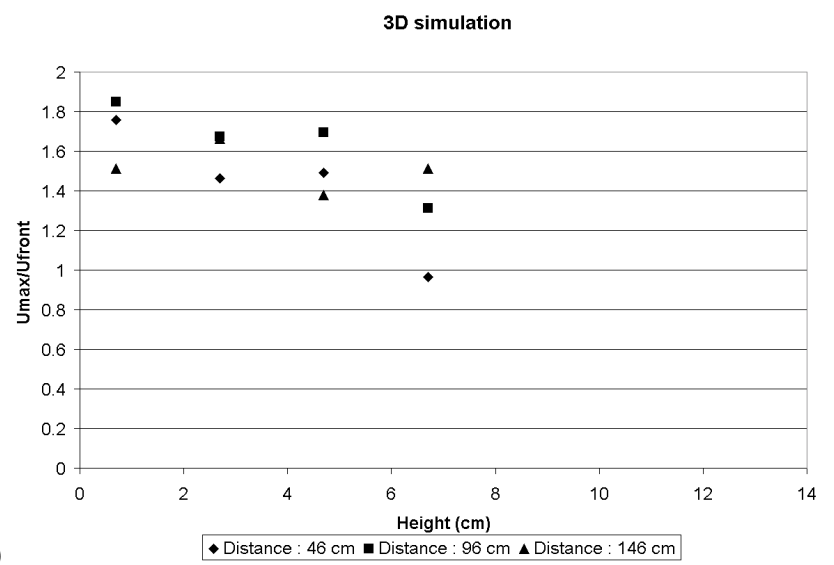

(b)

Fig. 9. (a) Values of $U_{\max } / U_{\text {front }}$ as a function of height for different distances for 2-D simulation. (b)Values of $U_{\max } / U_{\text {front }}$ as a function of height for different distances for 2-D simulation.

\subsection{Reference avalanche}

Figure 7 shows that in the front velocity $U_{\text {front }}$, there was an initial acceleration phase from the release gate (where $U_{\text {front }}=0$ ) followed by a deceleration phase. The velocity is weakly dependent on the initial conditions (slope, initial volume and density ratio) (Beghin and Olagne, 1991). The greater deceleration observed in the 3-D configuration is explained by the lateral growth of the avalanche. Figure 8 shows average values for a velocity time series. Since measurements were not automatically initiated but released manually, there was a random component in their position relative to the avalanche head. Since the maximum velocity is relevant for determining the maximum pressure, we have chosen to shift the maximum peaks of each run in order to have all the maxima at the same position, i.e. at the same time. The velocity just behind the nose in the head was greater than the front velocity. We observed the same structure in the 3-D configuration with a time lag due to the lower front speed.

In the 2-D simulation, the velocity maximum was about 1.5 times the front velocity, which is in accordance with Hopfinger's results. In both cases the slope was $10^{\circ}$, but Hopfinger and Tochon-Danguy (1977) suggest that there is a 
$2 \mathrm{~cm}$ above the ground

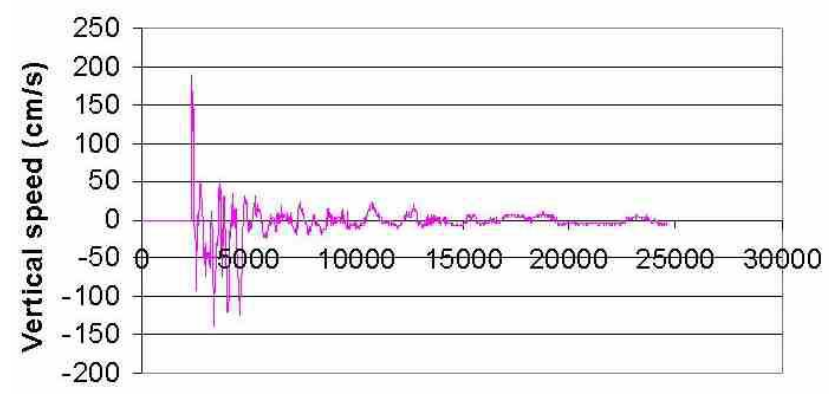

Time after the release $(\mathrm{ms})$

Fig. 10. Vertical velocity as function of time (3-D simulation).

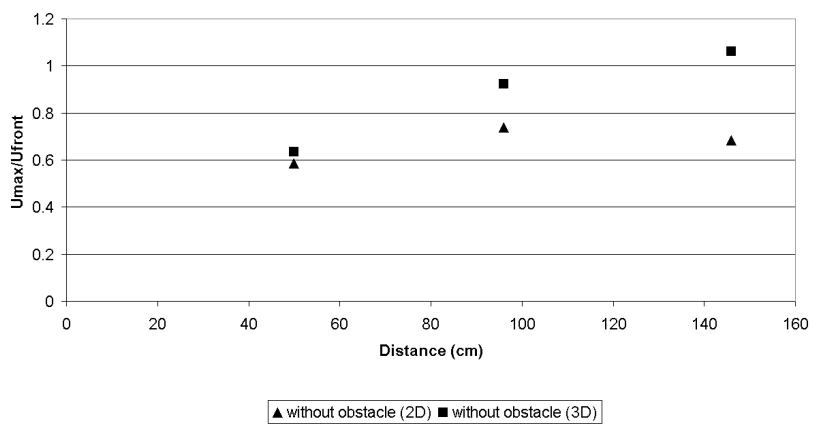

Fig. 11. Ratio between the maximum positive vertical speed (average over 5 runs) and the front velocity as a function of distance for 2-D and 3-D simulations.

slope-angle-dependence. But Keller's measurements (1995) in a 3-D configuration at angles from $30^{\circ}$ to $45^{\circ}$ did not reveal any slope dependence of this ratio: its values were 1.51.6 and remained so even on a horizontal run-out. According to the velocity profiles, this ratio fell with height (see Figs. 9a and $b$ ). However, there was no distance dependence: the distance corresponds to the distance covered by the avalanche. For the 3-D configuration (see Figs. 9a and b), the ratio differed slightly from those previously measured: it was even greater (up to 1.8 near the ground).

The frontal large eddy circulated in a counterclockwise direction (for a gravity current moving from left to right); this is the feature of the gravity currents or thermals with dominant air drag. It is translated in the following graph by a negative vertical velocity coming after a positive vertical velocity (see Fig. 10). At a given distance from the release tank, the positive vertical velocity was observed during a very short period. It is quite interesting to observe that the value (even for negative speed) of this vertical velocity rose to $106 \%(91 \%)$ of the front velocity for 3-D simulation and $74 \%$ (70\%) for 2-D simulation (see Figs. 11 and 12). This might explain why powder avalanches can lift small obstacles (trees, electric poles, cable-car pillars, even roofs).

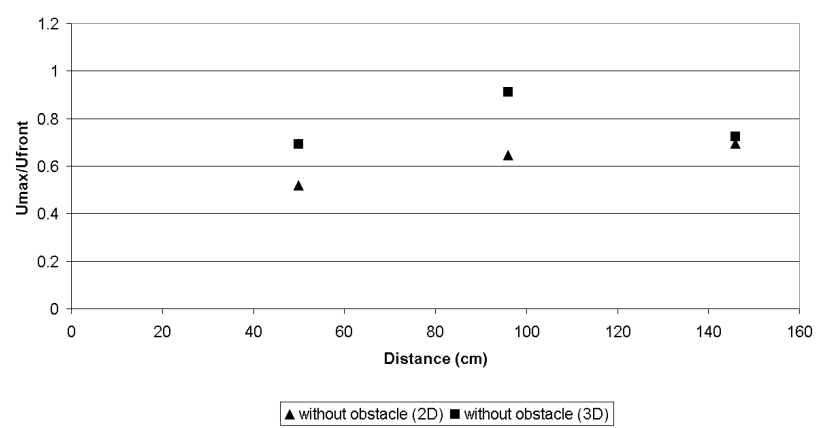

Fig. 12. Ratio between the maximum negative vertical speed (average over 5 runs) and the front velocity as a function of distance for 2-D and 3-D simulations.

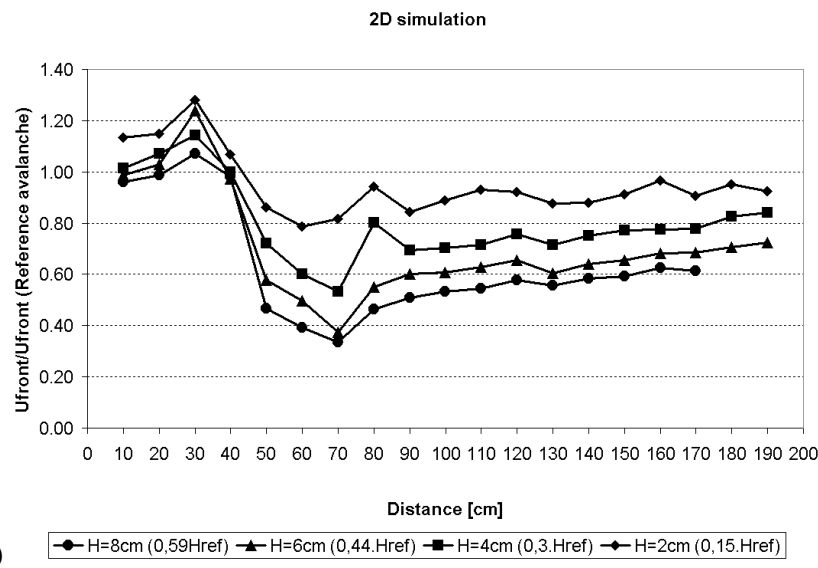

(a)

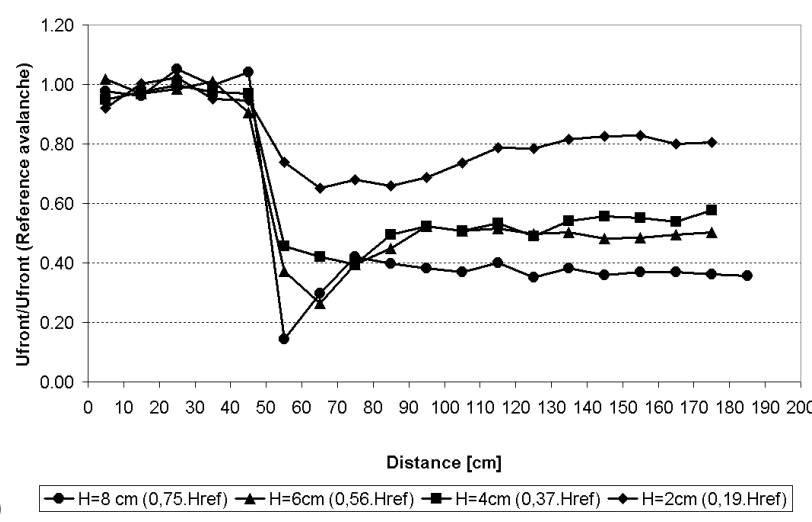

Fig. 13. (a) Values of $U_{\text {front }} / U_{\text {front, ref as a function of dis- }}$ tance for different dam heights (2-D simulation). (b) Values of $U_{\text {front }} / U_{\text {front, ref }}$ as a function of distance for different dam heights (3-D simulation).

\subsection{Effect of the dam}

In contrast to dense snow avalanches, powder avalanches behave like a turbulent Newtonian fluid. The flow overruns obstacles: the dam causes an acceleration of flow above it and then a vortex appears. This vortex acquires its circulation from the impulse due to the acceleration above the dam 


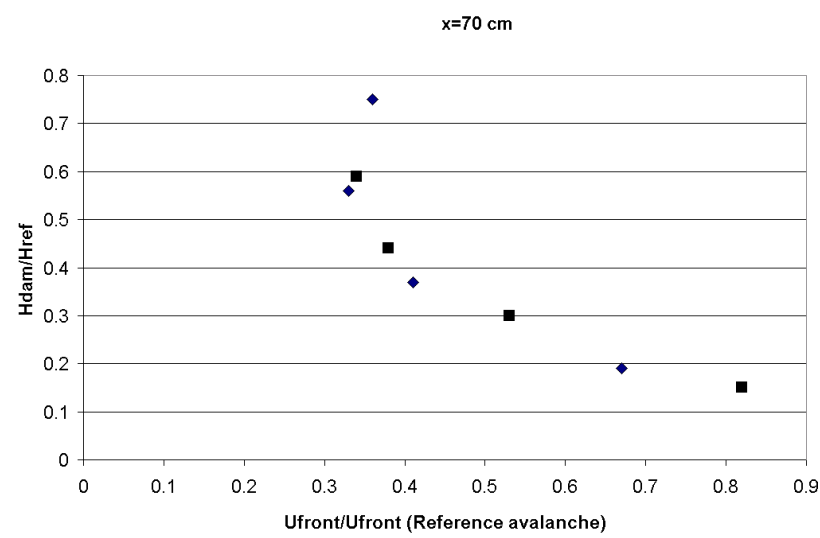

(a)
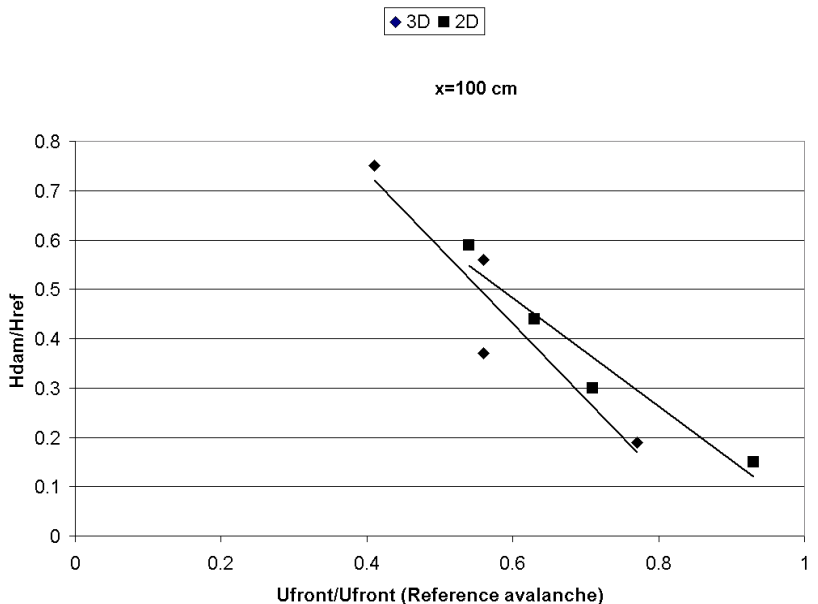

(b)

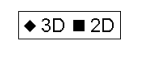

(a)

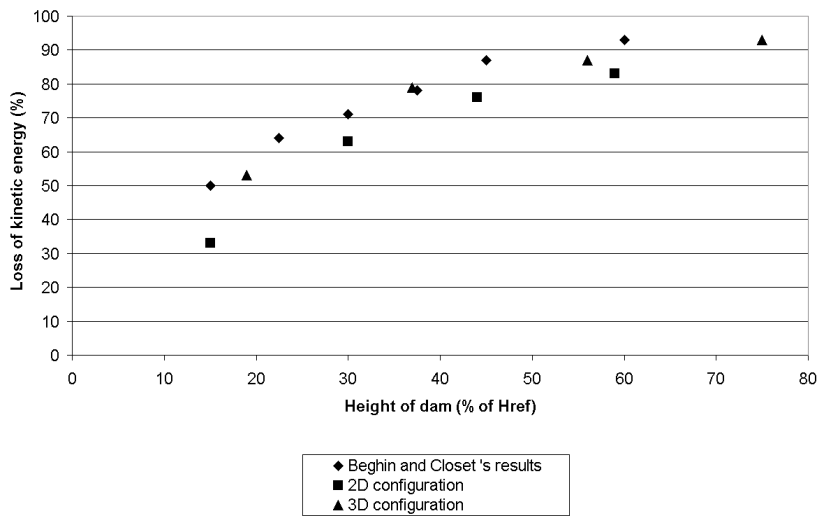

Fig. 15. Loss of kinetic energy as a function of dam height for different distances.
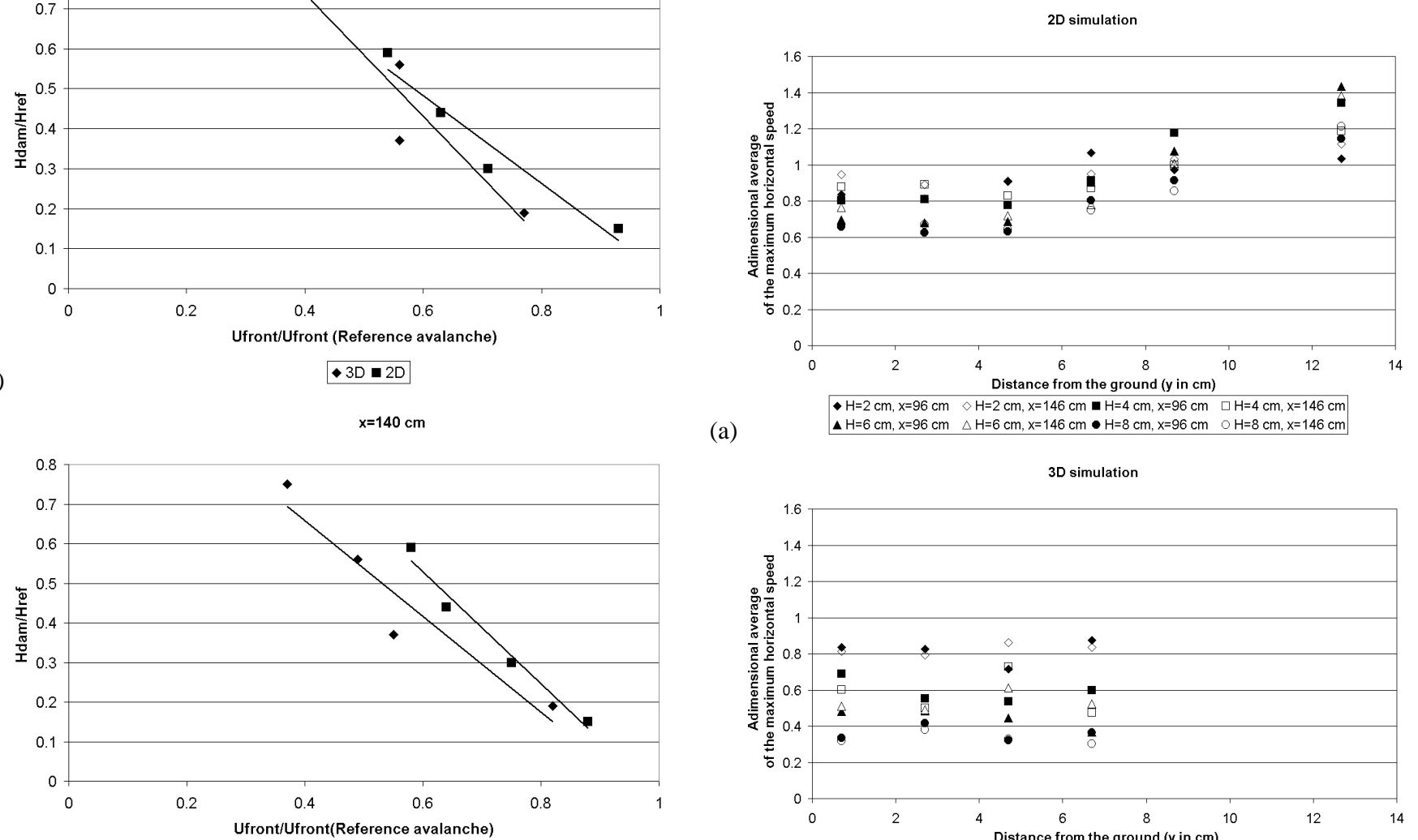

(c)

$\rightarrow 3 \mathrm{D}=2 \mathrm{D}$

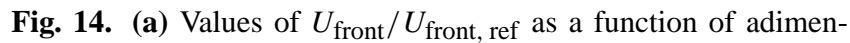
sional dam height at $x=70 \mathrm{~cm}$. (b) Values of $U_{\text {front }} / U_{\text {front, ref }}$ as a function of adimensional dam height at $x=100 \mathrm{~cm}$. (c) Values of $U_{\text {front }} / U_{\text {front, ref }}$ as a function of adimensional dam height at $x=140 \mathrm{~cm}$.

(Hopfinger and Tochon-Danguy, 1977). In our experiment, the reduction in the front velocity was an increasing function of the dam height. Furthermore, the larger the distance is from the dam, the smaller the reduction (see Figs. 13a and 13b). The dams are significantly more effective in the open-

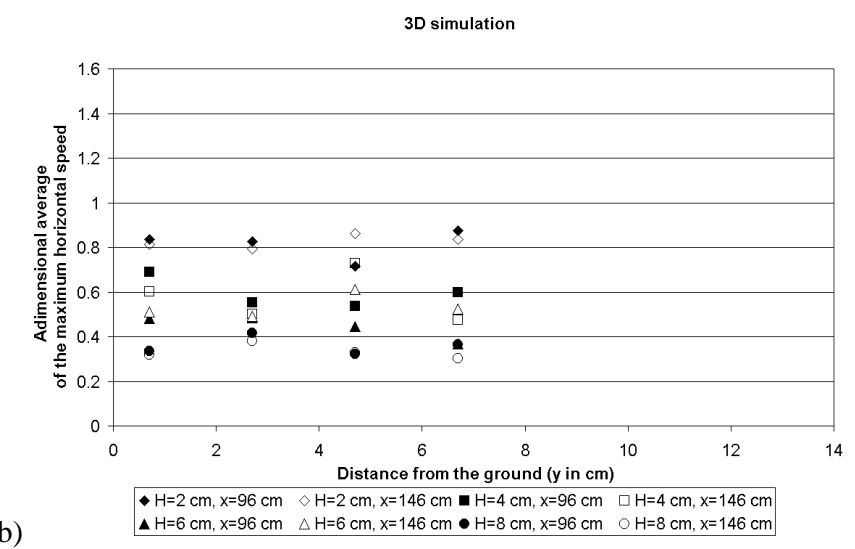

Fig. 16. (a) Ratio between the maximum horizontal speed with dam and without dam as a function of height for 2-D simulation. (b) Ratio between the maximum horizontal speed with dam and without dam as a function of height for 3-D simulation.

slope (3-D) configuration than in the channelled case. In the case of a channelled avalanche (2-D configuration), the adimensional front velocity was higher (see Figs. 14a-c). The lateral diffusion upstream of the dam on an open slope may explain this effect.

Beghin and Closet (1990) quantified the effectiveness of 
$2 \mathrm{D}$ simulation $(\mathrm{x}=96 \mathrm{~cm})$

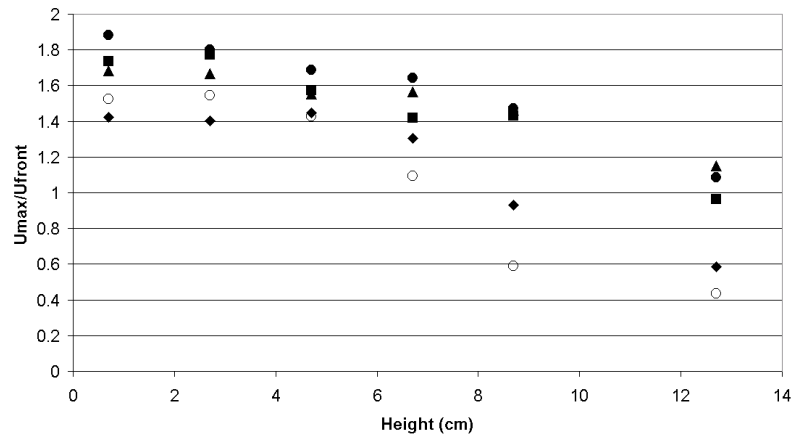

(a)

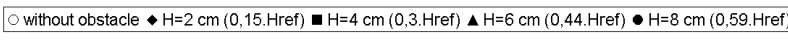

2D simulation $(x=146 \mathrm{~cm})$

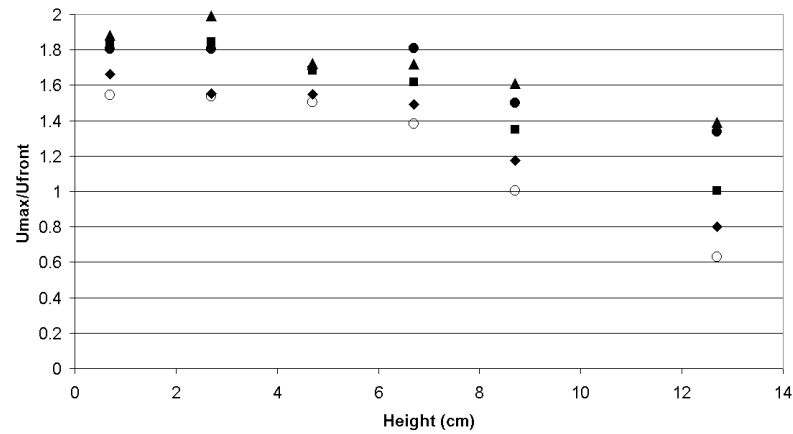

(b)

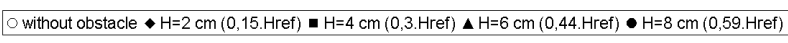

Fig. 17. (a) Ratio between the maximum horizontal speed (average over five runs) and the front velocity as a function of height for 2-D simulation at $x=96 \mathrm{~cm}$. (b) Ratio between the maximum horizontal speed (average over five runs) and the front velocity as a function of height for 2-D simulation at $x=146 \mathrm{~cm}$.

a dam in terms of the loss of kinetic energy due to the dam. This loss of energy was roughly estimated in the following formula:

$\frac{U_{r e f}^{2}-U_{d a m}^{2}}{U_{r e f}^{2}}$,

where $U_{\mathrm{dam}}$ is the average front velocity over a distance of $30 \mathrm{~cm}$ just beneath the dam and $U_{\text {ref }}$ is the average front velocity over the same distance for the reference avalanche.

Figure 15 shows that our results for the 3-D configuration are in good agreement with Beghin and Closet's results (the only difference between both experiments is the density ratio: 1.3 for Beghin and Closet experiments, 1.2 for ours). As stated before, the dams were less efficient in the case of a channelled avalanche: the loss of kinetic energy was approximately $10 \%$ less than for unchannelled flows.

But caution is needed when using the simple Eq. (1) above. Powder avalanches behave like Newtonian fluids. The dynamic pressure is given by $p=\frac{\rho u^{2}}{2}$. The maximum pressure is expected to occur for the maximum values in velocity and density. As mentioned by Hopfinger (1983), laboratory experiments show that the velocity inside the avalanche can be

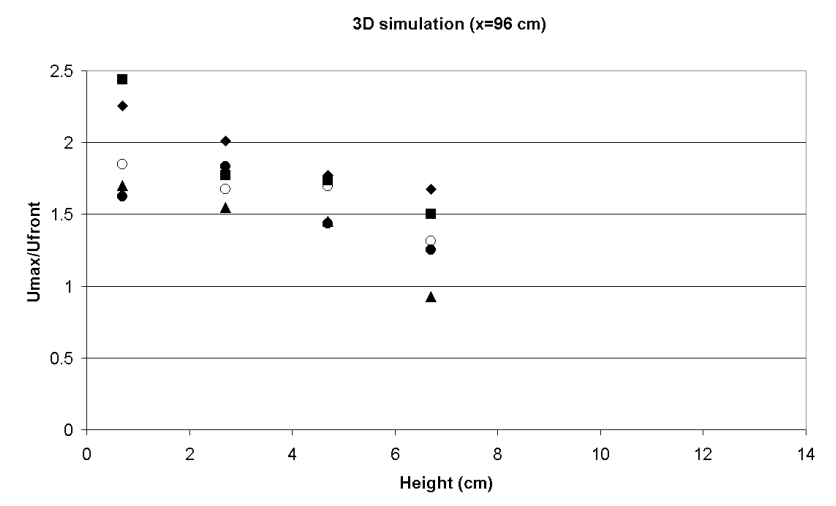

(a)
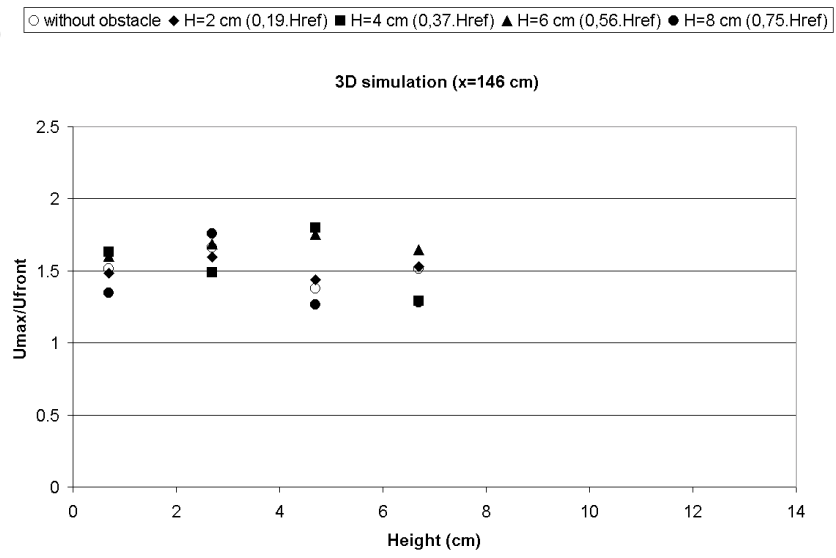

(b) O without obstacle $\bullet \mathrm{H}=2 \mathrm{~cm}(0,19 . \mathrm{Href}) \bullet \mathrm{H}=4 \mathrm{~cm}(0,37 . \mathrm{Href}) \Delta \mathrm{H}=6 \mathrm{~cm}(0,56 . \mathrm{Href}) \bullet \mathrm{H}=8 \mathrm{~cm}(0,75$. Href)

Fig. 18. (a) Ratio between the maximum horizontal speed (average over five runs) and the front velocity as a function of height for 3-D simulation at $\mathrm{x}=96 \mathrm{~cm}$. (b) Ratio between the maximum horizontal speed (average over five runs) and the front velocity as a function of height for 3-D simulation at $\mathrm{x}=146 \mathrm{~cm}$.

1.5-2.5 times the front velocity, and close to the ground the effective density is larger than the average density, by a factor 2 to 4 , in real powder snow avalanches. Therefore, the measured peak pressure can be larger, by a factor of 10, than the pressure calculated from the front velocity and the average velocity. Therefore, in the following paragraphs, we will deal with the maximum velocities (in fact the mean maximum velocity over five runs).

The reduction in velocity near the ground was about $50 \%$ in the 2-D configuration and 60\% in the 3-D configuration. In fact, the velocities appear to be redistributed rather than reduced. Figures $16 \mathrm{a}$ and $\mathrm{b}$ show that there was an acceleration of speed in the higher part of the profile, when the distance from the ground was of the same order as the reference height. In the lower part of the profile, even if there was no acceleration, one can see that the velocity reduction was an increasing function of its height. This trend was not so dominant in the 3-D configuration (Fig. 16b). However, one must bear in mind that the higher part of the speed profile was not studied due to the low value of speed in the experiments.

The previous studies of Beghin and Closet (1990) and Augé et al. (1995) refer to the front velocity. Considering 


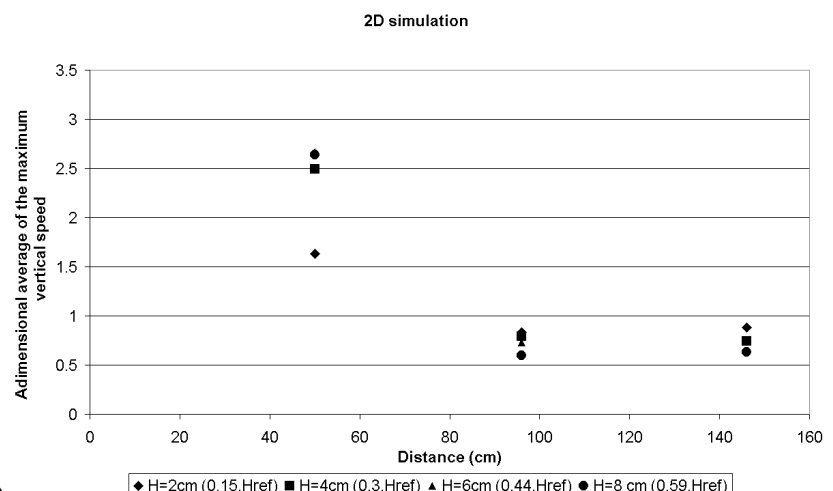

(a)

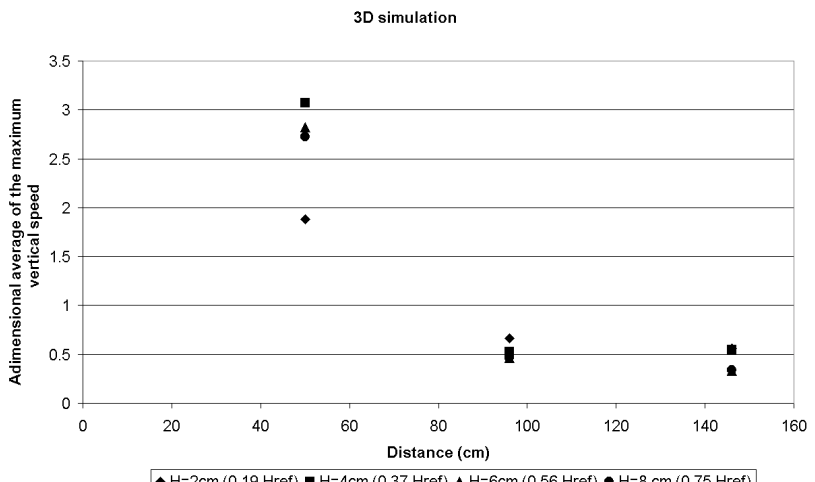

(b)

$\bullet \mathrm{H}=2 \mathrm{~cm}(0,19 . \mathrm{Href}) \unrhd \mathrm{H}=4 \mathrm{~cm}(0,37 . \mathrm{Href}) \backsim \mathrm{H}=6 \mathrm{~cm}(0,56 . \mathrm{Href}) \bullet \mathrm{H}=8 \mathrm{~cm}(0,75 . \mathrm{Href})$

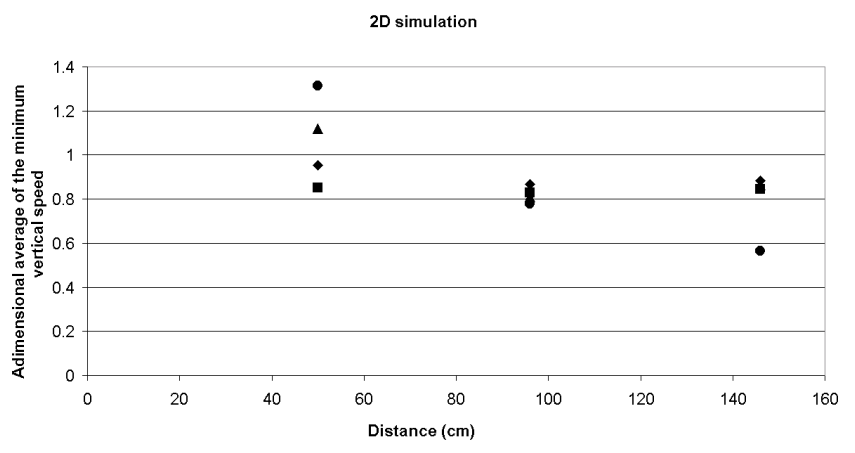

(a)

$\bullet \mathrm{H}=2 \mathrm{~cm}(0,15 . \mathrm{Href}) \square \mathrm{H}=4 \mathrm{~cm}(0,3 . \mathrm{Href}) \Delta \mathrm{H}=6 \mathrm{~cm}(0,44 . \mathrm{Href}) \bullet \mathrm{H}=8 \mathrm{~cm}(0,59 . \mathrm{Href})$

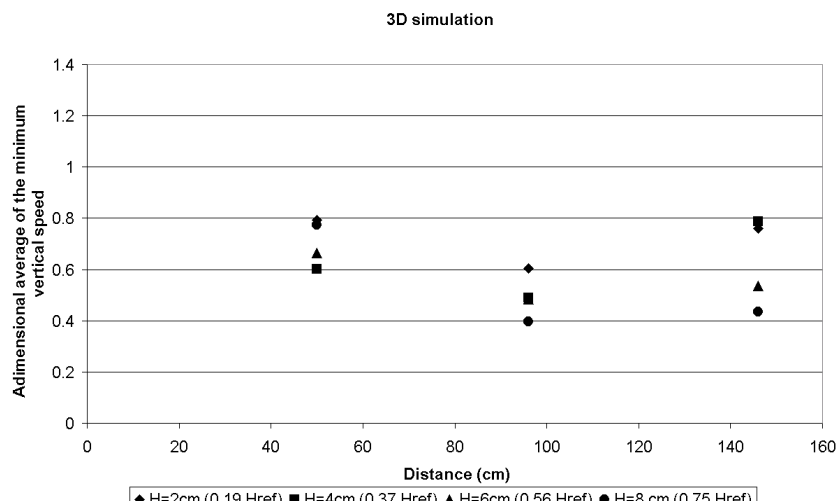

(b)

Fig. 19. (a) Ratio between the maximum positive vertical speeds (average over five runs) with and without dam as a function of distance for 2-D simulation. Four different dam heights were tested. (b) Ratio between the maximum positive vertical speeds (average over five runs) with and without dam as a function of distance for 3-D simulation. Four different dam heights were tested.

that the velocity just behind the nose in the head was greater than the front velocity, we studied the modification of the ratio between maximum velocity and front velocity as a function of dam height. For the 2-D configuration, this ratio was an increasing function of dam height and reached a value of 1.9; this means that the use of the front velocity led to an overestimation of a dam's effectiveness that became worse as the dam height was increased. This trend was not so pronounced in the 3-D configuration. Instead, we must keep in mind that the deviations from the mean were greater for the 3-D experiments: the averaging should probably have been made over seven or ten runs. Figures $17 \mathrm{a}, \mathrm{b}$ and $18 \mathrm{a}, \mathrm{b}$ report the results. The height of the undisturbed flow at the location of the dam was $13.5 \mathrm{~cm}(10.7 \mathrm{~cm})$ for the 2-D (3D) configuration. The dam caused an increase in the vertical velocity component just above it. The maximum vertical velocity above the obstacle was an increasing function of dam height in the range of the tested configurations. This velocity was about three times larger than the reference vertical velocity. This effect was more pronounced in 3-D simulations (see Fig. 19b). On the contrary, one can see that the positive and negative velocities decreased downstream of the obstacle (see Figs. 19a, b and 20a, b). This reduction was an increas-

Fig. 20. (a) Ratio between the maximum negative vertical speeds (average over five runs) with and without dam as a function of distance for 2-D simulation. Four different dam heights were tested. (b) Ratio between the maximum negative vertical speeds (average over five runs) with and without dam as a function of distance for 3-D simulation. Four different dam heights were tested.

ing function of the dam height and was more pronounced for the 3-D configuration. Nevertheless, it is rather difficult to interpret the results plotted in Figs. 18a, b and 19a, b, because the maximum positive (or negative) vertical speeds are not observed at the same heights for the reference avalanche and the avalanche with dams.

\section{Conclusions and further developments}

For the reference avalanche, the velocity just behind the nose in the head is greater than the front velocity. For the 2-D configuration, the ratio $U_{\max } / U_{\text {front }}$ can be 1.6 , but it depends on the height. For the 3-D configuration, this ratio differs slightly and it was even greater (up to 1.8 ). The vertical velocity is up to $87 \%$ of the front velocity for the 3-D simulation and $66 \%$ for the 2-D simulation.

The reduction in front velocity due to the presence of a dam is an increasing function of the dam height. But this reduction depends on the topography: dams are more effective on an open-slope avalanche (3-D configuration). The ratio $U_{\max } / U_{\text {front }}$ is an increasing function of the dam height and can reach a value of 1.9. Consequently, the front velocity is, therefore, not relevant in determining the effectiveness of 
dams. The obstacle leads to a reduction in vertical velocity downstream of the vortex zone.

In water-tank experiments, the injection can either be continuous or of short duration, as in our experiments. In this case, only a head (without a quasi-steady layer) is established. On a slope of $10^{\circ}$, the velocity maximum just behind the nose of the reference avalanche is about 1.5 times the front velocity. But in a steady density current, this velocity maximum is about 2.5 times the front velocity. For this reason, we intend to test the effect of a continuous injection in the near future.

Another important point is the density ratio. The applicability of our results to real powder snow avalanches is still an open question, mainly because the density ratio is not respected. This effect will be studied in a later part of the CADZIE project by means of numerical simulations. Moreover, the density distributions must be taken into consideration when calculating avalanche loads. In our experimental set-up, we did not have access to this data, but numerical simulations will yield information on this important point.

Acknowledgements. This research was supported by European Union (EVG1-1999-00009) in the framework of the CADZIE project (Catastrophic Avalanches Defence Structures and Zoning in Europe). The authors gratefully acknowledge the assistance of F. Ousset (Cemagref) and Ch. Eymond-Gris (Cemagref) for preparing experiments.

\section{References}

Augé, A., Ousset, F., and Marco, O.: "Effet d'une digue sur l'écoulement d'un aerosol", Proceedings of Chamonix Sympo- sium "The contribution of scientific research to safety with snow, ice and avalance", 235-240. 1995.

Beghin, P. and Closet, J.-F.: Effet d'une digue sur l'écoulement e l'avalanche poudreuse, Note technique du Cemagref, no. 77, Grenoble, 1990.

Beghin P. and Olagne X.: Experimental and theoretical study of the dynamics of powder snow avalanches, Cold Regions and Technology, 19, 317-326, 1991.

Bozhinskiy A. N. and Sukhanov, L. A.: Physical modeling of avalanches using an aerosol cloud of powder materials, Annals of Glaciology, 26, 242-246, 1998.

Hermann, F. and Hutter, K.: Laboratory experiments on the dynamics of powder-snow avalanches in the run-out zone, J. of Glaciology, 37, 126, 281-295, 1991.

Hopfinger, E. J. and Tochon-Danguy, J.-C.: A model of powdersnow avalanches, J. of Glaciology, 19, 81, 343-356, 1977.

Hopfinger, E. J.: Snow avalanche motion and related phenomena, Ann Rev. Fluid Mech., 15, 47-76, 1983.

Keller, S.: Measurements of powder snow avalanches: Laboratory, Surveys in Geophysics, 16, 661-670, 1995.

Keller, S. and Issler, D.: Staublawinen über Dämme und Mauern im Labor; Zusammenstellung aller Resultate und Auswertung, Internal report of the Swiss Federal Institute for Snow and Avalanche, Research no. 697, Davos (Switzerland), April, 1996.

Lane-Serff, B. L. M. and Hadfield, T. D.: Gravity current over obstacles, J. of Fluid Mechanics, 292, 39-53, 2000.

McClung, D. and Schaerer, P.: The Avalanche Handbook, The Mountaineers, Seattle, 1993.

Nishimura, K., Sandersen, F., Kristensen, K., and Lied, K.: Measurements of powder snow avalanche - Nature, Surveys in Geophysics, 16 649-660, 1995. 